\title{
The Anatomy of an Accident
}

ALBERT L. CHAPMAN, M.D.

A CCIDENT is a word applied to the culmination of a series of events which result in harm to the individual or damage to property. Accidents originate in unsafe acts. The end result of a small proportion of unsafe acts is an accident.

A small proportion of accidents result in accidental injuries. Accidental deaths are the end results of a very much smaller proportion of accidents.

In essence no accidental death, no accidental injury, in fact no accident, can occur unless it is preceded by an unsafe act.

Therefore, the most important element that accident prevention programs must seek to eradicate are unsafe acts themselves.

An example may serve a useful purpose. A man walking along a city street was hit on the head by a flowerpot. His skull was fractured. Two days later he died. Here was an accident, an accidental injury, and an accidental death. But where was the unsafe act?

Is it to be presumed that to be safe one must never walk on the sidewalks of a busy city street?

No! The victim of this accident engaged in no unsafe act, but - there was one-in fact there were at least two unsafe acts.

The mother who, to liven up her drab apartment, placed a potted plant on the window sill committed the first unsafe act. She had never been conditioned to think in terms of accident prevention. She gave no thought to the even-

Dr. Chapman is Assistant Surgeon General and chief of the Division of Special Health Services, Public Health Service. tual consequences of what she did. The child who leaned out of the window to peer at the crowd below and in so doing brushed the potted plant off the window sill committed the second unsafe act.

Other unsafe acts were involved, of course. The building should not have been built with sills directly over the sidewalks and there should have been regulations prohibiting such dangerous practices as putting a potted plant on a window sill.

If the first or third unsafe act had not occurred, the second unsafe act would not have been possible.

This illustration serves to demonstrate that individuals cannot by living safely, and behaving safely, always insure themselves against accidental injury or death due to the ignorance or carelessness of others.

Accident prevention indoctrination must be directed not only toward self-preservation but also toward the protection of others.

In considering ways and means of preventing accidental deaths and injuries then the aim must be to prevent, or at least to greatly decrease, the incidence of unsafe acts. This is true since no one can predict precisely which unsafe act will result in an accidental death or in an accidental injury.

This same illustration demonstrates this point. If no one had been in the path of the falling flowerpot, the two unsafe acts which were committed would have caused an accident (the breaking of the flowerpot), but there would have been no accidental injury or death.

An accident has several sides. One side is the environmental side-the flowerpot on the window sill over the sidewalk. Another side is the 
human, or biological side-the act of placing the flowerpot on the window sill could have been avoided, and even after the flowerpot was placed on the window sill it was only knocked off by the act of an individual.

All of us live in an environment which is potentially dangerous, even lethal, depending upon circumstances, some of which are subject to our own control-some of which are subject to the control of others.

There is no such thing as a "safe" environment. There can only be "safer" environments. Human behavior, conditioned by physical, physiological, and emotional factors of great degrees of complexity, determine the occurrence or nonoccurrence of accidents far more often than environmental factors per se.

There is no such thing as a "safe" person. However, persons who have been motivated, trained, and conditioned to behave safely are much "safer" individuals than persons not so motivated, trained, and conditioned.

No matter how thoroughly an environment has been screened for accident-causing potentials, an unsafe person may have an accident or may cause an accident to happen if the circumstances are right.

In addition then to emphasizing the need to help people to adapt themselves to living safely in whatever environment they find themselves, there is a co-equal need to change the environment in such a way that it is less likely to invite accidents.

The paucity of human and financial resources available for expenditures in educating, training, and conditioning individuals to adjust safely to their habitat makes it imperative to conduct studies, call them epidemiological if you will, that will identify those human characteristics which are most productive of accidents. If this is not done, our relatively meager resources will be expended on activities that have the potential for saving only a few lives while activities which have the potential for saving many lives are left undone.

Examples of the types of studies which can give direction to community safety activities are:

- Determining through surveys in homes the actual places where medicines and household poisons are stored.
- Investigating the causes of home fires: for example, faulty electrical wiring, mishandling of kerosene, and improper storage of flammable materials.

- Studying the circumstances surrounding drownings in a community. These can shed considerable light on causative factors, many of which are subject to correction: age, sex, and swimming ability of the person drowned; enclosure of fishponds and swimming pools; and artificial respiration attempted, if any.

This obvious plea to apply scientific counting methods in order to identify the major factors which cause accidents in each locality must, of course, be modified by the need to take advantage of the peculiar interest of each individual and of each community group.

Logic is quite alien to many community activities. Logic alone should not deter anyone from doing the best that can be done under existing circumstances.

Another major factor to be considered in mounting an attack on accidents is the existence or absence of specific measures which will prevent a certain type of accident.

For example, there may be widespread community interest in the development of a poison control program, yet there may be little interest in making radical changes in driver-licensing laws.

A local poison control program may have the potential of saving only 5 lives a year, whereas making the requirements for driver licensing much more drastic may have the potential for saving 50 lives a year in the same community.

The first program is much easier for the lay person to understand; it involves no great sacrifice of personal liberty, and it can actually be developed as a part of existing institutions and organizations.

The latter program is much more remotely associated with accident prevention; its beneficial effects are more difficult to appreciate, it involves more deprivation of personal liberty (a license), and hence must await the preparation of the community mind for its fulfillment. This may take many years.

In summary, then, the fundamental nature of accidents and the inevitable association of unsafe acts, accidental injuries, and accidental deaths must be imparted not only to community 
leaders but to the public-to the man on the street.

The fact that there can be no monopoly in accident prevention by individuals or groups is a basic tenet. Every person, every organization, and every agency has a personal as well as an organizational contribution to make to the safety movement.

Leadership, of course, can best stem from specific organizations whose sole function is to prevent or bring about the prevention of accidents. I am speaking specifically of the National Safety Council and State and local safety councils associated with the National Safety Council.

Finally, a simple truth must be implanted firmly in every mind; namely, that accidents don't happen, they are caused - they are caused by what people do or by what they fail to do.

Acceptance of this truth means that one must admit that since human action can be modified, accidents with rare exceptions are preventable occurrences, and that the same resources mobilized to combat heart disease, cancer, and mental illness should be committed in much larger amounts to the prevention of accidents.

\section{Radiological Health Curriculums in Schools of Public Health}

Within the past few years radiological courses have been introduced into most schools of public health, and curriculums specializing in radiological health are currently being offered at several schools. In addition, certain schools have developed a general radiological course which may be included in the curriculum for those students having only an ancillary interest in radiological health. Radiological health training in schools of public health concerns health agencies because radiation safety programs employ many radiation specialists with basic training in biology, chemistry, physics, and engineering. To provide leadership and direction in this field requires personnel versed in radiation and public health.

Schools offering specialized training include Harvard, Johns Hopkins, Pittsburgh, and Michigan. The curriculums initially developed at these schools varied significantly, both in number and types of courses required for an advanced degree. The current trend, however, appears to be toward development of curriculums incorporating basic public health courses plus radiological courses. The public health courses may include epidemiology, biostatistics, and public health administration, whereas the radiological courses include radiobiology, radiation physics, radiation protection and control, and other topics. Flex- ible rather than rigid or standard programs also appear to be the general trend.

During this transitional and developmental stage of these radiological health curriculums, the schools are interested in exchanging opinions concerning both the quantitative and qualitative aspects of these curriculums. For example, they ask what is the probable demand for radiological health specialists, and are there sufficient university resources to meet these needs? What should be the basic or minimum curriculum for schools specializing in radiological health? To what extent should all school of public health graduates be trained in radiological health? Is further curriculum specialization indicated, directed toward dosimetry, radioecology, biophysics, or political science?

An important aspect in resolving the latter question is the scope of other radiological health training programs being offered in other areas, for example, in schools of medicine and engineering, or in health physics or radiation biophysics programs. Essentially, the status of curriculum development in each of these areas is comparable to that in schools of public health. Thus, it is likely that they would also like to exchange viewpoints and information.
In an effort to provide this opportunity for university personnel, the Division of Radiological Health of the Public Health Service is planning to sponsor a 3-day symposium this summer on the topic "University Curricula in Radiological Health." The symposium will be held August 2-4, 1960, in Princeton, N.J. University staff members, principally from schools of public health, medicine, and engineering, will be invited to participate in the discussions. Altogether, the purposes of this symposium will be to discuss: ( $a$ ) requirements for radiological health personnel, ( $b$ ) trends and experience in development of basic radiological health curriculums for various professional disciplines, and (c) staffing, cost, and other problems associated with university radiological health programs.

It is hoped that the symposium being planned, whereby representatives of universities, professional societies, and health agencies may jointly contribute, will assure an orderly progress in the field of radiological health training and thereby further the application of nuclear technology with full regard to the safety of present and future generations.-Donald A. Pecsok, acting chicf, Training Branch, Division of Radiological Health, Public Health service. 